\title{
The conscious life - the dream we live in
}

\author{
Fr. Lect. Cosmin Tudor Clocan, PhD \\ Faculty of Orthodox Theology, \\ Ovidius University of Constanta \\ ROMANIA \\ cosmin.ciocan@univ-ovidius.ro
}

\section{ARTICLE INFO}

\section{Article history:}

Received 12 February 2017

Received in revised form 18 April

Accepted 10 May 2017

Available online 30 May 2017

doi: 10.18638/dialogo.2017.3.2.5

Keywords:

consciousness; awareness;

phenomenology; artificial intelligence;

Self-conscious; awakening;

circumstantial;
ABSTRACT

It is most likely for anyone to ask himself at least once if it would be possible to live in a dream? Questioning the fabric of "reality" we live in consciously was one of the main doubts man ever had. It is so likely for us to answer positive to it due to so many factors; starting from the many and various facets of reality each individual envision the world, from the enormous differences we all have while perceiving and defining the reality, etc. That is why, at the conscious level, life seems almost like a dream in a dream, always hoping to wake up from the negative, unwanted version of it. That is why my assertion here, based on latest theories on consciousness and AI (artificial intelligence), aim to say that we live in between reality and dream, being "conscious" of ourselves, but not really wanting to be "aware" of what is really going on with us.

(c) 2014 RCDST. All rights reserved.

\section{INTRODUCTION}

We have heard many times that the information is everything, and numbers (like 1 , for example) stands for the fundamental base of everything. A binary chart has been created to describe any object, thing or existence we have information about. A choice of only two possible values for each digit: 0 and 1 , a digital encoding/decoding system in which there are exclusively precisely these two possible states for anything. I would like to take this idea of a simple system and process it for the dialogue of the actual terms Self-Soul-Consciousness.

It has been asked in this conference whether we can level up these three terms using one of them as a criterion. I would propose to take awareness as the primary criterion and level everything else after this one, since I consider that the binary system works not only for the exact sciences but for everything else, religion and psychology as well. 


\section{THE CONSCIOUSNESS ISSUE}

Assuming that the assertion that the existence of any kind of consciousness at the 'things' created by humans (i.e. clones and $\mathrm{Al}$, artificial intelligence) is invalid and that the possibility that Al would benefit from the advantages of a Self, aware of itself, is but a speculation, until present time (at least) we cannot sustain with technological support. That leads us saying for now that consciousness is entirely a humanly possession.

\section{A. What is the establishment of the Consciousness?}

In the serial movie 'WestWorld'[1] the complicated discussion between the creator of $\mathrm{Al}$ individuals, Bernard Lowe (himself an Al, an anagram of "Arnold Weber", the inventor of this amusement park) and his main and top Al creation, Dolores Abernathy, about consciousness, illustrates two possible constructions of it: the pyramidal[2] and the maze one. Each of them is based on the elements-leveling consciousness, i.e. memory, improvisation, self-interest, and suffering. The combination of these elements, unique and almost aleatory, gives birth to Consciousness. Seen as a pyramidal construct, the Consciousness is fundamentally based on memories stored after a preliminary management, a subjective stacking value, and a personal interpretation of the saved events. Then, since humans tend to deviate from their routine it looks like the mind rearranges these fundamental pieces in different, new order each time and within each person improvising to new outputs. Most of the times the decisions are taken to prevent humans from hurting themselves, in a preservation instinct or self-interest.

Another construction of consciousness is that of a maze, in which all psychological elements constitute the passages of the maze, and the individual, with each decision and option he makes, positions - same as the ball in a toy maze -closer either to the center (the key of consciousness) or the edges. In this perspective - more verisimilar in several points - we find consciousness efficient in any direction the ball heads: either towards edges, in a potential exit out, or to the center, towards the finding of the maze-key. In any scenario consciousness helps individual to cross the path he chooses, reconciled with choice made. This way it is not surprising that, even if the individuals are endowed with consciousness, the situations in which awareness became self-awareness are very rare, in a conjunction between consciousness and Self-conscious.

\section{B. The backstory: Predestination and conscious choices}

Looking from above the social scene it was always asked if some people worth more than others, and if YES, if the "others" can be sacrificed for one to survive? From the ancient politics to present time's ethics this remains the question with circumstantial answers. Still, considering the actual theme, we can conclude that each individual lives his life within a back-story, considered for him alone, with a role to play, so that everything is perfectly set and followed. Now, considering this scenario, we are coming back in the theological loop of questioning: if so, there is any chance for each individual to make his own choices or everything is only put into act like a paper role that unfolds discovering new, but already predestined things? The answer we would prefer is that we make our own choices, which we are in control of our lives. Therefore, even if we play a role predetermined for us, it would be "easier to digest" the assertion that it is our consciousness that makes the choices how to do things, if not possible to determine if we are doing it or not. This is the last possibility/barrier of becoming Self-aware. First to understand that I am; then to position myself in a social frame and the trick is now not to assume too much of this position, since it can change with so many others without sticking to one in particular. Any philosophical meditation on the subject aims to say that, if I assume too much of a social frame 
position/role, then it traps me with its duties ..., leaving me no chance of getting more of myself. Moreover, that leads us to question what consciousness is (like)?

The idea with this back-story is that it is employed to lend depth or believability to the main story or to create a distraction from the real thing we live in. It is presented so detailed and thorough that we always became captivated by its rigorously and captured by the story. It has been nominated for the best trap ever for so many times and by various civilizations and thinkers that it is almost impossible not to grant it this title. The main part in the backstory is played by the memory or the recollection, for it allows "the writer" to bring forth information from earlier in the story or from before the beginning of the story. Sometimes taken as the real story we all have our reveries in which we duplicate and transpose ourselves for another, more convenient side of life. It is not unusual for psychopathology to deal with people escaped from physical reality into a backstory artificially created by their minds and nonetheless 'real' for the characters/people with psychotic disorders. Without any known or treating cranial trauma, these psychotic or delusional people act entirely healthy and normal, but outside of the social, common physical reality, as if they would play in a theatrical roleplay, conscientious built an entirely different reality with all dissimilar set of rules and characters. These medical diagnoses of specific psychiatric diseases provide a large spectrum of what reality means for the mind and how can it replenishes entirely and authentically.

However, there is no need to go so far with a strong-case exemplification since we have an example at our fingertips. Everybody arranges his life around criteria, a key-concept and objective; everybody leads his or her life towards a purpose, well-determined or on the road, but none the less a meaningful life. The few persons whose lives lack purpose make a final statement out of this and commit suicide. All others live in a way to fulfill the aim we settle, regardless its quality and effectiveness. Even if we strive to get the 'bare necessities', to place a simple thing in life's carousel, or to discover the stars we abut, the life of each of us targets a precise and pursued acquisitively. In this key-concept the exterior, sensitive reality became organized around it, and things without any significance to it almost inexistent, fading under the brilliance of the determined aim. In this scenario can we say that, regardless the actual proposal, we all live in a personal backstory built by our minds and entirely different from others'? I think we do, that is why I have submitted this suggested theory of multi-layered reality in which each of us handles a different position. Is this backstory acknowledged or not? Are we aware of this trapping scenario and do it forward 'on purpose', or we are living 'unconscious' about its existence as a backstory? Moreover, if so, could we wake up from this slumber? Moreover, what possible catalysts could stop the process of trance? these are the main questions my proposal have to answer to.

\section{THE AWAKENING}

Starting with Platon's Myth of the cage[3] to Matrix series along with many other pro-science movies the humans were always imagined as if they are not part of a single, explicit reality, but of a scenario carefully optimized for us. This backstory we are not being aware of and we live it like we are in a dream, is either created for us or projected by us in a way the reality is personalized and made easier to live in, easier to digest it. The Allegory of the cage scenario is well-known by all for its proposal of a certain alpha memory one character became aware of and thus he awakes from the backstory he and his companions were plugged in. Plato imagines a cave where people have been imprisoned from birth and by this imprisonment these prisoners are chained so that their legs and necks are fixed, forcing them to gaze at the wall in front of them and not look around at the cave, each other, or themselves ( $514 a-b)$. Socrates suggests that the shadows are the reality for the prisoners because they have never seen anything else; they do 
not realize that what they see are shadows of objects in front of a fire, much less that these objects are inspired by real things outside the cave (514b-515a). The fixation towards the cave's screen is nothing else but the trap I have linked the backstory with one's mind; it simply cannot escape it since he never acquaints anything but shadows and puppets (514b).

First of all, what is the motif of being 'trapped' into such a backstory, what would be the meaning of that oneirism? In all these allegories the motif appears always the same: to give life a personal meaning, to stop us from getting out in a reality that cannot be understood. Why is that? Because everything man cannot encompass with knowledge frightens him, makes him anxious. Facing a void man can jump only if he is tackled to, convinced that 'everything is OK out there'. "One of the most prevalent fears people have is that of losing control, the fear that if you don't manage to control the outcome of future events, something terrible will happen. The crux of the problem is the demand for certainty in a world that is always tentative and uncertain. You think that you must accurately predict and manage the future, not just have some probabilistic and uncertain handle on it."[4] In this category of giving meaning for escaping anxiety of losing control [over life] we can list: knowing the precise time [first thing most people do after waking up - from a sleep, coma, or long absence - is inquiring about the time]; entering an unclear water; entering a dark room/ building/cave/tunnel; death. For each of these losing-control anxiety cases and so many others the will of having a spoken whatever meaning is enough for moving on. Facing such situations we need/demand a valuable explanation - and it doesn't have to be the real, ultimate one, just the perfect one - so that we can overcome the stalemate. It is mind calming to hear a certain 'it will be alright', even if we know it isn't, but somehow our mind calms down. Psychology have discovered that our minds are built in that way that even if it search for knowledge, it calms down with anything and it doesn't have to be true. It simply creates this backstory by itself, as if it would be its purpose. The ultimate evidence for that is the routine. Our mind is built to stand on a habitual way of living. We never stay on 'new' too long; we live the 'first' moment with uncertainty and anxiety and we quickly transform it in a routine. Human mind is made to think in patterns so it always builds it from anything, transforming all into skills. Every new encounter becomes soon a habit, an inurement. It needs to, it must to. Otherwise we cannot move on to the next step, to the next level of living. Always new, routineless is not our thing, we cannot step on quicksand. But if we do, if we have to at certain points in life, we definitely ask for a story that makes us step on it with the ambition that we master it. It is almost like the riders do with their horses when entering a burning field: they place a wrap around their eyes so that the horses place trust entirely on their riders' eyes and will. Same way our minds demands: a story for everything, and it doesn't have to be the real one, anything can do the trick as long as it is believed as real. We can enter a dark room if we are told no harm will be there, we can swim in water with sharks if we are told that there is nothing else but algae there; we do not fear death, if we are told Elysium awaits for us to live a blessed and happy life, and indulging in whatever employment they had enjoyed in life[5]. That is the main reason religion is defined as ontological to humans, for it is not entirely about theology, but about things we need to believe in in order to move on in life, to get a significance on things science and discoveries cannot encompass [yet]. In dark we cannot know, but we can get to experience it only if we believe so first. That is why science came after religion, and knowing after believing. Again, either way, knowing and believing, science and religion, does not need to be the real thing; it is enough to give us a significance over things we encounter so that we move on making that story a trustful routine and a flying carpet.

This need of having a whatever backstory is the key-element for our minds to continue living and experiencing things. It is thou the self-sustaining power for the consciousness Self: not to be aware of the backstory, but 
to be Self-aware in the position he plays in it. Consciousness is not about why I am doing that, but that I am doing it. If for whatever reason a character awakes from a backstory his mind instantly creates another one based on the first thing he encounter outside the cave, as it would prevent him to discover more and quicker, or to ever know the truth. The human mind is so powerful in creating self-sustaining-backstories so that it builds an entire universe story based only on a couple of bright spots he sees in the dark[6].

It doesn't matter if there are sharks in the water as long as your story calms my anxiety and makes me swim. It doesn't matter if there are beasts in the cave as long as the story tells me things my mind requires to step in fearless. It certainly doesn't matter if beyond death there is or there is not another life as long as the story tells me I am welcomed there and my mind allows me then to let go my beloved ones which dye or gives me strength to do heroic, lethal acts. As far as I (my conscious Self) know all these backstories are the only one that exist and there is no thing that (can) contradict it for my mind will instantly deny any counterproof that tries to awake me from my backstory I lean on trustfully. And, in the pattern designated by this theory, even if proofs succeed in waking me up, my mind instantly find a first thing to build up a new, stronger and more balanced backstory and continue to sleepwalking day and night.

What difference does it make if the universe I find shapes as a wrap around the Earth, as an infinite void, as a finite tire, or as a file in a multipage book? For my mind (conscious Self) takes this whatever initial premise and build a whole stable story fitting the premise we were primarily fed with. Same way goes with religious explanations: in every religious culture different backstories are built based on whatever tales are told so that minds get their 'brainstorming keyelement' to start with and get rid of the anxious "I don't know that".

I cannot be sure about the veracity of nothing [i.e. any theory], but I can definitely trust on anything that makes me move on any obstacle. I cannot 'scientifically' appoint a consciousness in itself, but I can say for sure I am a conscious Self in whatever backstory I live in. maybe a story that encompasses all the backstories does not exist, as well as a multiverse encompassing all our verses and layered realities can definitely be possible. Bua a fact is most certain here: "there is no crack in the forest if there is no conscious self to hear it"[7]. Therefore, if would be a story (reality) encompassing all our subjective backstories, this would be only possible if there is a consciousness that can be(come) aware of its existence, and so that conscious Self would fill the alpha story with his consciousness. That is probably the Buddhist perception of the universal Spirit/Consciousness. But then again, if the ultimate story encompassing all is filled with a highest self-consciousness, it would not make that a backstory for that ultimate consciousness, aka trapping it with a narcotic dream? Maybe for this particular reason and thought the Christian story of a Creator place Him entirely outside the creation, transcending it while He fills it in every atom.

\section{HABITUATION AND CONSCIOUSNESS OR THE UNCONSCIOUS MIND}

I have said earlier that our mind is designed 'to stand on a habitual way of living'. Let's talk some about this idea in the end of this paper.

We all have agreed that consciousness forms memories and, vice-versa, memories are a proof of being conscious. On the other hand, there is no need for a Self to PROVE itself for other Selfs to be conscious for it to BE conscious, right? This except in the assertions of solipsism that was already spoked about previously with the perception and the awareness about a crack-noise. Out of this theory the existence of something doesn't have to be proven in order for it to exist[8], but it is not the place for us to re-discuss thoughts already been in debates and targeted by the philosophical talk.

The definition psychology has for habituation 
and its origination is the tendency to have decreased responsiveness to something. For that matter "Something that is new and incredibly exciting can become annoying."[9] For example, there may be a painting you really like so you place it near you, on your desk. You take time to watch it for a while every day, 10 times a day. Over time and repeated exposures to this painting you might start get the feeling that you have "seen it a million times" and it just doesn't have the same effect on you that it used to or that it had first time(s). This is habituation. Certain noises in a house cause a newborn baby to cry, until he or she becomes desensitized to the noises and they no longer frighten the child. This is also habituation.

First of all we know that, even under the patronage of consciousness, a memory cannot be recorder outside of a stimulus. This must be external and it gets an internal response to it, one that makes us conscious about it and allows us create a memory out of it. In other words, we mostly get 'pictures', "portions of life" if conscious; I said 'mostly' since we consciously want/need to select these portions we want to inhabit our mind as memories. However there is prove that we unconscious record memories and these are exponentially more the former. From S. Freud until neuroscience the theory of 'the unconscious mind' has been developed with lots of objective evidence. It represents "the reservoir of feelings, thoughts, urges, and memories that outside of our conscious awareness. Most of the contents of the unconscious are unacceptable or unpleasant, such as feelings of pain, anxiety, or conflict. According to Freud, the unconscious continues to influence our behavior and experience, even though we are unaware of these underlying influences."[10] The motivation of these unconscious memories is not yet settled. Freud, for example, "believed that many of our feelings, desires, and emotions are repressed or held out of awareness. Why? Because, he suggested, they were simply too threatening. Freud believed that sometimes these hidden desires and wishes make themselves known through dreams and slips of the tongue (aka "Freudian slips")."[11] Computational neuroscience however asserts that brain functions and the information processing properties of the structures that make up the nervous system is mostly unconscious and we continually record everything that surround us without paying any attention. There are thus non-understandable items that can recollect, reactivate and reveal those memories. These items seem to be aleatory and meaningless, but they can relate to the unconscious memories as a missing piece of a puzzle: once you have it into your sight you instantly recollect the landscape it was taken from. There are theories that emphasis this idea, starting from the psychoanalytic hypnotic regression, or the Rorschach test, saying that memories of habitual deeds live long after the conscious control ends.

\section{REFERENCES}

[1] An American science fiction thriller television series created by Jonathan Nolan and Lisa Joy for HBO, based on the 1973 film of the same name, which was written and directed by American novelist Michael Crichton. The first episode premiered on October 2, 2016.

[2] A reference to Maslow's Pyramidal Hierarchy of Needs (1943, 1954), a motivational theory in psychology comprising a five tier model of human needs, often depicted as hierarchical levels within a pyramid. These first five levels were upgraded with additional three, looking in the end to: 1. Biological and Physiological needs; 2. Safety needs; 3. Love and belongingness need; 4. Esteem needs; 5. Cognitive needs; 6. Aesthetic needs; 7. Self-Actualization needs; and 8. Transcendence needs. Internet link: http:// www.simplypsychology.org/maslow.html (accessed 6.2.2017).

[3] Plato, The Republic (514a-520a), online source: http://www.gutenberg.org/ ebooks/1497.

[4] Elliot D. Cohen, "The Fear of Losing Control", in Psychology Today, posted May 22, 2011. Retrieved from https://www. psychologytoday.com/blog/what-would- 
aristotle-do/201105/the-fear-losing-control.

[5] Daniel Ogden, A Companion to Greek Religion. Singapore: Blackwell Publishing, 2007, pp. 92, 93. ISBN 1-4051-2054-1.

[6] A by the way on scientifically assertions man has built in history from insignificantly 'discoveries'.

[7] Philosopher George Berkeley, in his work, $A$ Treatise Concerning the Principles of Human Knowledge (1710), proposes, "But, say you, surely there is nothing easier than for me to imagine trees, for instance, in a park [...] and nobody by to perceive them. [section 23] [...]. He developed the subjective idealism, a metaphysical theory to respond to these questions, coined famously as "to be is to be perceived". Scientific American, April 5, 1884, pg 218: "Sound is vibration, transmitted to our senses through the mechanism of the ear, and recognized as sound only at our nerve centers. The falling of the tree or any other disturbance will produce vibration of the air. If there be no ears to hear, there will be no sound". Burt Harding, "There is no sound if a tree falls in a forest and nobody is in range to hear it. Our senses tell us the world is real. I truth, it's a play of mind." And so on.

[8] This the notorious debate between realism and idealism, whether or not things are in our minds or in themselves, out of senses, per se or $\alpha \rho \chi \alpha 1$. See Pierre Aubenque, Le problème de I 'être che Aristote, PUF. Paris, 1966.

[9] Habituation. (n.d.). In Alleydog.com's online glossary. Retrieved from: http:// www.alleydog.com/glossary/definition-cit. php?term=habituation

[10] Kendra Cherry, What Is the Unconscious? Freud's conceptualization of the unconscious, in "verywell.com". references from Freud, S. (1915). The unconscious. Standard Edition, Volume 14. Retrieved from https://www.verywell.com/what-is-theunconscious-2796004.

[11] Ibidem.

\section{BIOGRAPHY}

Ciocan Tudor Cosmin, born in Constanta/ Romania in 1977, I have attended several theological and psychological schools (BA, $\mathrm{MB}, \mathrm{PhD}$ ), obtained my PhD in Missiology and Doctrinal Theology in 2010. I was ordained as orthodox priest in 2002. High-school teacher from 1998, then Professor assistant and Lecturer from 2012, I have written more than 30 papers on theology and psychology, along with 4 single author books in the past two decades.

In 2013 started a multidisciplinary program aiming to engage scholars from different files into friendly and academic debates with theology and in the same year a Research Center was founded in Ovidius University with researchers from 11 fields. in lest then 1 year I manage to gather people from around the globe around this idea and so we have started Dialogo Conferences project. In 2014 I received a Fulbright scholarship and I spent the summer California and 4 other States in USA, gathering data and understanding how religious pluralism is possible at a high level of involvement; in the same time I made friends from many different countries and religions that are now involved in this project or another, helping in his endeavor.

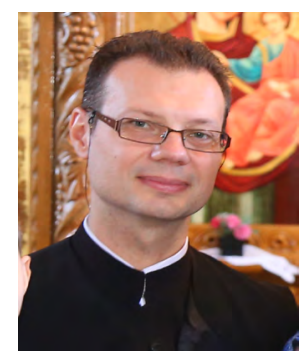

